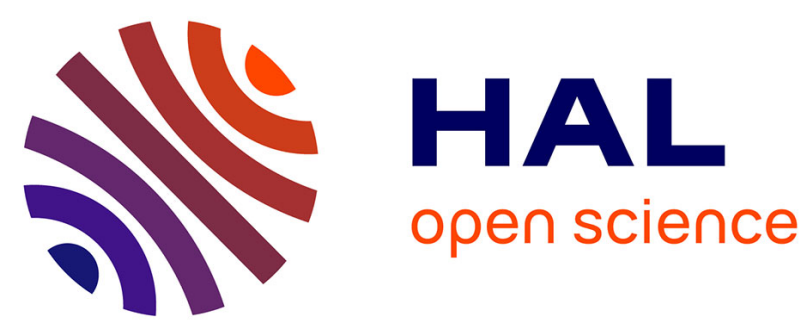

\title{
First evidence for allotriploid hybrids between Juniperus thurifera and J. sabina in a sympatric area in the French Alps
}

Perla Farhat, Najat Takvorian, Maria Avramidou, Luc Garraud, Robert P. Adams, Sonja Siljak-Yakovlev, Magda Bou Dagher Kharrat, Thierry Robert

\section{To cite this version:}

Perla Farhat, Najat Takvorian, Maria Avramidou, Luc Garraud, Robert P. Adams, et al.. First evidence for allotriploid hybrids between Juniperus thurifera and J. sabina in a sympatric area in the French Alps. Annals of Forest Science, 2020, 77 (4), pp.93. 10.1007/s13595-020-00969-7 . hal03354950

\author{
HAL Id: hal-03354950 \\ https://hal.science/hal-03354950
}

Submitted on 27 Sep 2021

HAL is a multi-disciplinary open access archive for the deposit and dissemination of scientific research documents, whether they are published or not. The documents may come from teaching and research institutions in France or abroad, or from public or private research centers.
L'archive ouverte pluridisciplinaire HAL, est destinée au dépôt et à la diffusion de documents scientifiques de niveau recherche, publiés ou non, émanant des établissements d'enseignement et de recherche français ou étrangers, des laboratoires publics ou privés. 


\title{
First evidence for allotriploid hybrids between Juniperus thurifera and J. sabina in a sympatric area in the French Alps
}

\author{
Perla Farhat $^{1,2}$ (D) Najat Takvorian ${ }^{2,5} \cdot$ Maria Avramidou $^{2} \cdot$ Luc Garraud $^{3} \cdot$ Robert P. Adams $^{4} \cdot$ Sonja Siljak-Yakovlev $^{2}$. \\ Magda Bou Dagher Kharrat ${ }^{1}$. Thierry Robert ${ }^{2,5}$
}

Received: 16 November 2019 / Accepted: 28 May 2020 / Published online: 25 September 2020

(C) INRAE and Springer-Verlag France SAS, part of Springer Nature 2020

\begin{abstract}
- Key message Discovery of the first case of allotriploid juniper in a wild population in the French Alps where the parental species occurs in sympatry.

- Context Interspecific hybridization and polyploidy are important evolutionary phenomena in vascular plants. Natural hybridization between species living in sympatry can sometimes occur. Less frequent are successful hybridizations between species having different ploidy levels. At Saint Crépin location (French Alps), where sympatry between the tetraploid Juniperus thurifera and the diploid Juniperus sabina occurs, three individuals with an atypical morphology have been observed.

- Aims Prospect interspecific hybrids and interspecific genetic introgression occurrence.

- Methods Flow cytometry was employed to screen ploidy levels. Four chloroplast markers, nrDNA (ITS), and AFLP markers were used to unravel hybridization and potential introgression events. Variability of pollen size and morphology was assessed to have a first insight on the regularity of microsporogenesis in hybrids.

- Results The three putative hybrids were shown to be triploids. Molecular data demonstrated that these individuals were hybrids originated from a cross between J. sabina and J. thurifera and suggested that a backcross at least with $J$. thurifera is possible. Male triploid hybrids produced heterogeneous pollen and displayed evidence of irregularity in the microsporogenesis.

- Conclusion This study sheds light on a rare case of hybridization in a natural sympatric population of two Juniperus species with different ploidy levels. This mechanism might have been an important driver for the evolution and diversification of this coniferous genus.
\end{abstract}

Keywords Juniperus $\cdot$ Polyploidy · Interspecific hybridization $\cdot$ Pollen abnormality · AFLP · Saint Crépin

Handling Editor: Bruno Fady

Perla Farhat

perla.farhat@net.usj.edu.lb

Najat Takvorian

najat.takvorian@upmc.fr

Maria Avramidou

maria.avramidou@u-psud.fr

Luc Garraud

l.garraud@cbn-alpin.fr

Robert P. Adams

Robert_Adams@baylor.edu

Sonja Siljak-Yakovlev

sonia.yakovlev@u-psud.fr

Magda Bou Dagher Kharrat

magda.boudagher@usj.edu.lb
Thierry Robert

thierry.robert@u-psud.fr

1 Laboratoire Biodiversité et Génomique Fonctionnelle, Faculté des Sciences, Université Saint-Joseph, Campus Sciences et Technologies, Mar Roukos, Mkalles, BP: 1514 Riad el Solh, Beirut 1107 2050, Lebanon

2 Ecologie Systématique Evolution, Université Paris-Saclay, CNRS, AgroParisTech, 91400 Orsay, France

3 Conservatoire Botanique National Alpin, Domaine de Charance, 05000 Gap, France

4 Biology Department, Baylor University, Box 97388, Waco, TX 76798, USA

5 Biology Department, Sorbonne Université, 4 place Jussieu, 75005 Paris, France 


\section{Introduction}

Natural interspecific hybridization is an important evolutionary process and a common phenomenon in vascular plants implicated in ca. $40 \%$ of 282 families and $16 \%$ of 3212 genera (Whitney et al. 2010). Even though interspecific hybridization is common in vascular plants, it is concentrated in some groups, mainly polyploid, such as Orchidaceae and in some geographical locations (Atlantic, Mediterranean, and Alpine biogeographic regions) where hybridization hotspots were previously reported (Marques et al. 2017; Whitney et al. 2010). The evolutionary importance of this phenomenon resides in its possibility to enhance genetic diversity and species adaptation and may lead to speciation (Kerbs et al. 2017; Mallet 2007). Moreover, interspecific hybridization can arise without or with whole-genome duplication defined, in that second case as "allopolyploidization" and classified as one of the most common mechanisms of speciation in sympatric areas (Soltis and Soltis 2009).

In conifers, interspecific hybridization was shown to be more common than polyploidization except for Juniperus L., in which both phenomena are well represented (Ahuja 2005; Farhat et al. 2019a; Husband et al. 2013; Neale and Wheeler 2019).

Juniperus species are evergreen trees and shrubs of Cupressaceae family. This genus is considered as the most diversified inside its family. It is a monophyletic genus with approximately 75 species classified in three monophyletic sections: Caryocedrus Endlicher, Juniperus Spach, and Sabina (Miller) Spach (Adams 2014; Farjon 2005; Mao et al. 2010). They are widely distributed in the Northern Hemisphere except for $J$. procera Hochst. ex Endl., the only species distributed in the Southern Hemisphere (Adams 2014). This wide distribution of juniper species is mainly due to their tolerance to extreme environmental factors (Kukowski et al. 2013; Mathaux et al. 2016; Noble 1990; Rawat and Everson 2012), allowing them to adapt to diverse habitats. Indeed, species from this genus are found from the sea level until high altitudes, in forests and deserts, on rocky cliffs and sand dunes (Adams 2014; Díez-Garretas and Asensi 2014; Douaihy et al. 2012; Farjon 2005; Mathaux et al. 2016; Pinna et al. 2015). In addition, wide overlapping geographical distributions of Juniperus species and varieties occur (Adams 2014). Based on their morphology, potential hybrids between juniper species either with the same or different ploidy levels have been described in sympatric locations in Spain (Aparicio and Uribe-Echebarría 2006, $2008,2009)$. They are supposed to be hybrids between $J$. sabina L. $(2 n=2 x)$ and J. phoenicea L. $(2 n=2 x)$ (Juniperus $\times$ herragudensis J.M. Aparicio \& P.M. UribeEchebarría), between $J$. thurifera L. $(2 n=4 x)$ and $J$. phoenicea $(2 n=2 x)$ (Juniperus $\times$ palancianus J.M.
Aparicio \& P.M. Uribe-Echebarría), and between $J$. thurifera $(2 n=4 x)$ and J. sabina $(2 n=2 x)$ (Juniperus $\times$ cerropastorensis J.M. Aparicio \& P.M. Uribe-Echebarría) (Aparicio and Uribe-Echebarría 2006, 2008, 2009). Besides, hybridization was commonly reported between closely related diploid juniper species in areas of sympatry in North America, as for example, between J. virginiana L. var. silicicola (Small) Silba and $J$. bermudiana L.; $J$. osteosperma (Torr.) Little and J. occidentalis Hook. (Adams and Wingate 2008; Terry et al. 2000). Recently, in the French Alps, based on morphological observations, hybridization between $J$. thurifera and $J$. phoenicea and between $J$. thurifera and J. sabina was suspected to occur (Garraud and Abdulhak 2014).

Six juniper taxa are native to the French Alps. Three taxa of section Juniperus: Juniperus communis L. subsp. communis and subsp. nana (Hook.) Syme, J. oxycedrus L., and the other three taxa belong to section Sabina: J. sabina, J. thurifera, and J. phoenicea (Lebreton et al. 2013). Their distribution in this region was well surveyed by the National Alpine Botanical Conservatory (CBNA). Interestingly, sympatric occurrence between the tetraploid $J$. thurifera and the diploid J. sabina was reported particularly in Saint Crépin forest (Garraud and Abdulhak 2014; Lebreton et al. 2013). These two dioecious species have a very different distribution and morphology. The Western Mediterranean J. thurifera is a tree with a pyramidal crown that often grows to $20 \mathrm{~m}$ in height, compared with the Eurasian J. sabina, which is a shrub less than $1 \mathrm{~m}$ in height except in Mongolia and Spain. However, in the Sierra Nevada, it forms a horizontal shrub (Adams 2014; Adams and Schwarzbach 2006; Perez-Latorre and Cabezudo 2009). In general, both species have slightly overlapping phenology at the end of the winter (Adams 2014). Remarkably, potential hybrids between these two species with atypical morphology were described in sympatry at Saint Crépin location (Garraud and Abdulhak 2014; Lebreton et al. 2013). However, no genetic data are yet available to confirm their hybrid status.

In this study, we aimed to investigate the occurrence of hybridization between the tetraploid $J$. thurifera and the diploid J. sabina in Saint Crépin forest.

Considering the ploidy level difference between the potential parental species, we determined by flow cytometry the ploidy level of putative hybrids and parents. Molecular DNA markers were also used to confirm the hybrid status as well as to gain a first insight into the possible occurrence of interspecific introgression through backcross. Since meiosis abnormalities are common in interspecific hybrids, we aimed to assess the regularity of the microsporogenesis in the putative hybrids. In this goal, an observation of pollen size and morphology was carried out. Pollen size was used as a proxy to discuss the potential diversity of male gamete cytotypes produced by the studied taxa. 


\section{Material and method}

\subsection{Studied area and plant material}

The studied area was the Saint Crépin forest in the department of "Hautes-Alpes" in the South of France. The site's substrate was limestone. Altitude ranged from 1100 to $1250 \mathrm{~m}$ a.s.l. with moderate slopes. Three putative hybrids (JTS8, JTS14, and JTS19) have been identified in this locality based on their shape. They are semi-prostrate shrubs with ascending branches: JTS8 is a female shrub of $50 \mathrm{~cm}$ tall, JTS14 is a male shrub of $80 \mathrm{~cm}$ in height, and JTS19 is a male shrub of 2 $\mathrm{m}$ in height (Fig. 1).

Leaf samples of 24 individuals of $J$. thurifera, 11 individuals of $J$ sabina, and the three putative hybrid individuals (JTS8, JTS14, and JTS19) were collected and directly preserved in silica gel before analysis. All samples were used for the AFLP study.

A sub-sampling was selected from the entire sampling for further detailed analyses comprising six individuals of J. thurifera (JT2, JT3, JT5, JT9, JT16, JT39), six individuals of J. sabina (JS1, JS4, JS13, JS17, JS22, JS33), and the three putative hybrids (Table 1; Fig. 2).

Male cones from three $J$. thurifera male trees (JT2, JT3, JT9), three $J$. sabina male shrubs (JS13, JS22, JS33), and the two male potential hybrids (JTS14, JTS19) were collected and dried.
Herbarium specimens of all the trees analyzed in this study have been conserved in the herbaria of the National Alpine Botanical Conservatory.

\subsection{Genome size measurement}

Preparation of samples belonging to the sub-sampling and flow cytometry analysis for genome size assessment were performed as described in Farhat et al. (2019b).

\subsection{DNA extraction}

Total genomic DNA was extracted by the cetyltrimethyl ammonium bromide (CTAB) method (Doyle and Doyle 1990) according to the modifications for conifers elaborated by Bou Dagher-Kharrat et al. (2007). Approximately, $30 \mathrm{mg}$ of dried leaves were ground in a $2 \%$ CTAB solution. The DNA was quantified and diluted to a concentration of $50 \mathrm{ng} / \mu \mathrm{L}$.

\subsection{Polymerase chain reaction on cpDNA and nrDNA genetic markers}

ITS and four chloroplast regions (petN/psbM; tmL/trnF; $\operatorname{trnS} / \operatorname{trnG}$; $\operatorname{trnD} / \operatorname{trnT}$ ) were amplified from extracted DNA of the sub-sampling. Each Polymerase chain reaction (PCR) reaction contained 10 pmol of each forward and reverse primer
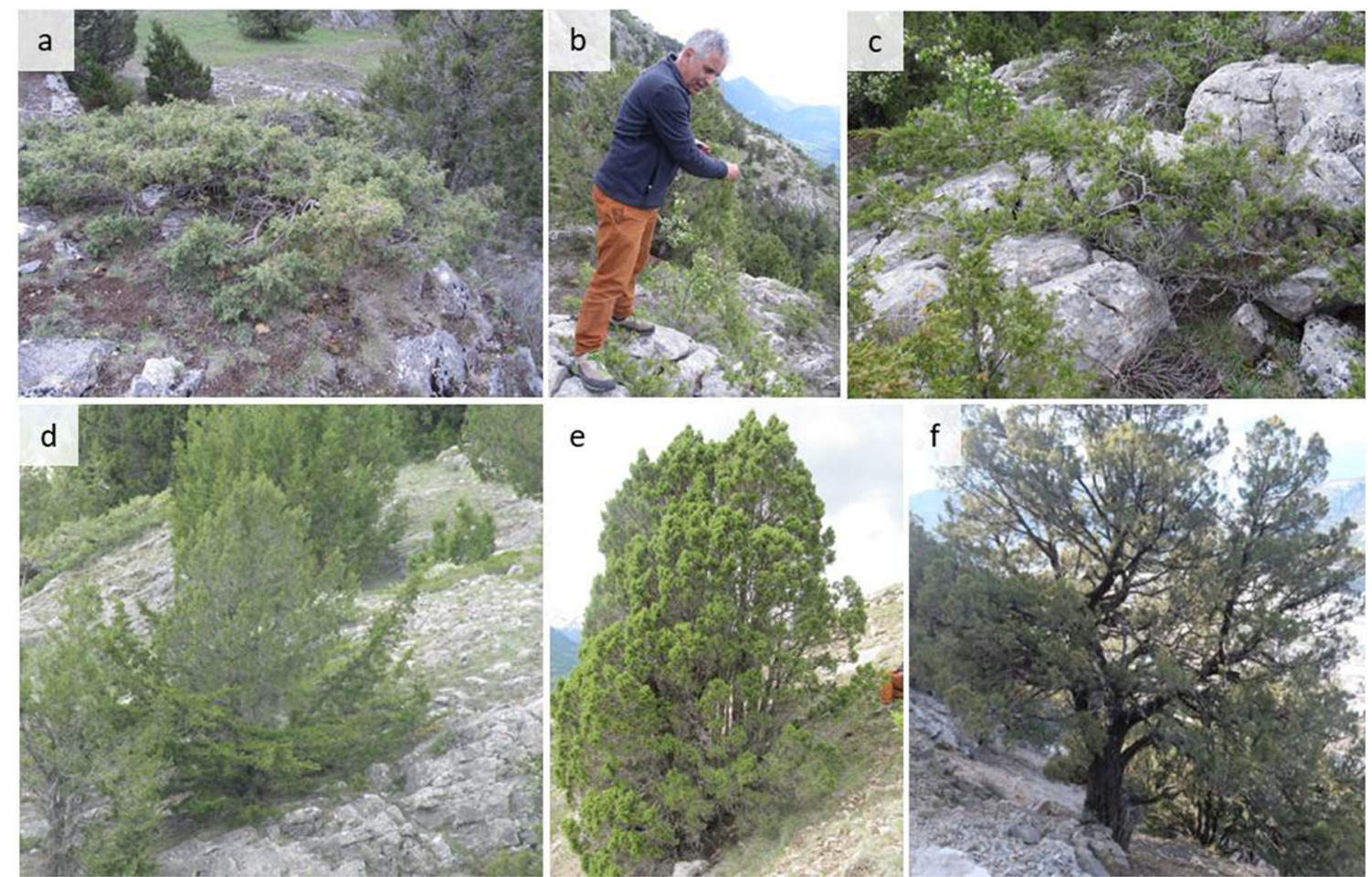

Fig. 1 Putative hybrids at Saint Crépin forest. a Represents the semi prostrated shrub JTS8. b and c More focused pictures for JTS14 representing the erected edge of the shrub. d Shrub JTS19, showing its

semi prostrated feature. e and f Global view of the tetraploid JT28 (e) and JT39 (f) with a clear "thurifera" architecture type 
Table 1 Details of the individuals belonging to the sub-sampling, their genome size values (2C/pg), and the corresponding coefficient of variation (CV). Sample abbreviation corresponds to J. thurifera (JT), J. sabina (JS), and putative hybrids (JTS)

\begin{tabular}{|c|c|c|c|c|c|c|c|}
\hline Species & $\begin{array}{l}\text { Sample } \\
\text { abbreviation }\end{array}$ & Gender & $\begin{array}{l}\text { Altitude } \\
(\mathrm{m})\end{array}$ & GPS & $\begin{array}{l}\text { Genome size } 2 \mathrm{C} / \\
\text { pg }\end{array}$ & $\begin{array}{l}\text { CV sample } \\
(\%)\end{array}$ & $\begin{array}{l}\text { CV standard } \\
(\%)\end{array}$ \\
\hline J. thurifera & JT2 & Male & 1200 & $\begin{array}{l}\mathrm{N} 44^{\circ} 43^{\prime} 14.8^{\prime \prime} \\
\mathrm{E} 6^{\circ} 36^{\prime} 01.8^{\prime \prime}\end{array}$ & 47.53 & 3.42 & 3.67 \\
\hline J. thurifera & JT3 & Male & 1220 & $\begin{array}{l}\mathrm{N} 44^{\circ} 43^{\prime} 17.1^{\prime \prime} \\
\mathrm{E} 6^{\circ} 36^{\prime} 3.224^{\prime \prime}\end{array}$ & 44.93 & 3.92 & 3.32 \\
\hline J. thurifera & JT5 & Male & 1220 & $\begin{array}{l}\text { N } 44^{\circ} 43^{\prime} 16.767^{\prime \prime} \\
\text { E } 6^{\circ} 36^{\prime} 3.185^{\prime \prime}\end{array}$ & 46.08 & 4.47 & 2.24 \\
\hline J. thurifera & JT9 & Male & 1240 & $\begin{array}{l}\mathrm{N} 44^{\circ} 43^{\prime} 15.828^{\prime \prime} \\
\mathrm{E} 6^{\circ} 36^{\prime} 3.982^{\prime \prime}\end{array}$ & 45.32 & 3.35 & 2.89 \\
\hline J. thurifera & JT16 & Male & 1230 & $\begin{array}{l}\mathrm{N} 44^{\circ} 43^{\prime} 14.755^{\prime \prime} \\
\mathrm{E} 6^{\circ} 36^{\prime} 6.05^{\prime \prime}\end{array}$ & 46.35 & 3.59 & 2.68 \\
\hline J. thurifera & JT39 & Male & 1060 & $\begin{array}{l}\mathrm{N} 44^{\circ} 42^{\prime} 44.25^{\prime \prime} \\
\mathrm{E} 6^{\circ} 36^{\prime} 24.802^{\prime \prime}\end{array}$ & 44.77 & 3.65 & 3.23 \\
\hline J. sabina & JS1 & Male & 1200 & $\begin{array}{l}\mathrm{N} 44^{\circ} 43^{\prime} 14.9^{\prime \prime} \\
\mathrm{E} 6^{\circ} 36^{\prime} 01.7^{\prime \prime}\end{array}$ & 23.19 & 3.19 & 3.39 \\
\hline J. sabina & JS4 & Un-determined & 1220 & $\begin{array}{l}\mathrm{N} 44^{\circ} 43^{\prime} 16.981^{\prime \prime} \\
\mathrm{E} 6^{\circ} 36^{\prime} 3.278^{\prime \prime}\end{array}$ & 23.32 & 3.21 & 2.84 \\
\hline J. sabina & JS13 & Male & 1220 & $\begin{array}{l}\mathrm{N} 44^{\circ} 43^{\prime} 14.868^{\prime \prime} \\
\mathrm{E} 6^{\circ} 36^{\prime} 3.932^{\prime \prime}\end{array}$ & 23.36 & 3.41 & 1.85 \\
\hline J. sabina & JS17 & Male & 1240 & $\begin{array}{l}\mathrm{N} 44^{\circ} 43^{\prime} 15.14^{\prime \prime} \\
\mathrm{E} 6^{\circ} 36^{\prime} 5.382^{\prime \prime}\end{array}$ & 23.47 & 4.15 & 2.69 \\
\hline J. sabina & JS22 & Male & 1250 & $\begin{array}{l}\mathrm{N} 44^{\circ} 43^{\prime} 13.632^{\prime \prime} \\
\mathrm{E} 6^{\circ} 36^{\prime} 10.528^{\prime \prime}\end{array}$ & 23.37 & 3.52 & 3.52 \\
\hline J. sabina & JS33 & Male & 1150 & $\begin{array}{l}\text { N } 44^{\circ} 42^{\prime} 53.087^{\prime \prime} \\
\text { E } 6^{\circ} 36^{\prime} 17.049^{\prime \prime}\end{array}$ & 22.77 & 4.00 & 4.12 \\
\hline $\begin{array}{l}\text { J. sabina } \times \\
\text { J. thurifera }\end{array}$ & JTS8 & Female & 1240 & $\begin{array}{l}\mathrm{N} 44^{\circ} 43^{\prime} 16.132^{\prime \prime} \\
\mathrm{E} 6^{\circ} 36^{\prime} 4.478^{\prime \prime}\end{array}$ & 34.08 & 2.92 & 2.99 \\
\hline $\begin{array}{l}\text { J. sabina } \times \\
\text { J. thurifera }\end{array}$ & JTS14 & Male & 1230 & $\begin{array}{l}\mathrm{N} 44^{\circ} 43^{\prime} 14.268^{\prime \prime} \\
\mathrm{E} 6^{\circ} 36^{\prime} 5.071^{\prime \prime}\end{array}$ & 34.63 & 3.3 & 2.59 \\
\hline $\begin{array}{l}\text { J. sabina } \times \\
\text { J. thurifera }\end{array}$ & JTS19 & Male & 1240 & $\begin{array}{l}\mathrm{N} 44^{\circ} 43^{\prime} 15.453^{\prime \prime} \\
\mathrm{E} 6^{\circ} 36^{\prime} 5.975^{\prime \prime}\end{array}$ & 35.35 & 3.5 & 2.5 \\
\hline
\end{tabular}

(Table 4 in Annex 2), $0.2 \mathrm{mM}$ of each dNTPs, $1 \mathrm{X}$ DreamTaq Buffer (Thermo Scientific), 2.5 units of DreamTaq DNA Polymerase (Thermo Scientific), and $100 \mathrm{ng}$ of genomic DNA in a final volume of $50 \mu \mathrm{L}$. PCR was performed using a Gene Amp PCR System 9700 set with an initial denaturation step at $95^{\circ} \mathrm{C}$ for $3 \mathrm{~min}$ followed by 30 cycles at $95^{\circ} \mathrm{C}$ for $30 \mathrm{~s}$, annealing temperature depending on the primers (Table 4 in Annex 2) for $30 \mathrm{~s}, 72^{\circ} \mathrm{C}$ for $1 \mathrm{~min}$, and a final extension step at $72{ }^{\circ} \mathrm{C}$ for $10 \mathrm{~min}$.

In order to determine the sequences of the haplotypes in the potential hybrids, PCR amplicons of ITS from these potential hybrids were cloned. The cloned amplicons were obtained by using the Taq DNA polymerase (MP Biomedicals). In each reaction, $100 \mathrm{ng}$ of genomic DNA was added to 10 pmol of each ITS forward and reverse primer, $0.2 \mathrm{mM}$ of each dNTPs, $1 \mathrm{X}$ Taq DNA polymerase buffer with $25 \mathrm{mM} \mathrm{MgCl}_{2}$, and 2.5 units of Taq DNA polymerase. The PCR was performed using the cycling parameters: initial denaturation at $94{ }^{\circ} \mathrm{C}$ for $1 \mathrm{~min}$, followed by 27 cycles at $94{ }^{\circ} \mathrm{C}$ for $1 \mathrm{~min}, 61^{\circ} \mathrm{C}$ for $1 \mathrm{~min}, 72^{\circ} \mathrm{C}$ for $1 \mathrm{~min}$, and a final extension at $72^{\circ} \mathrm{C}$ for $5 \mathrm{~min}$.

\subsection{Cloning}

Ligation of the fresh PCR product into pCR®2.1 vector (Thermo Scientific) was performed in a final volume of 10 $\mu \mathrm{L}$ following the manufacturer's instructions. Then, $2 \mu \mathrm{L}$ of the ligation product was added to $50 \mu \mathrm{L}$ vial of frozen One Shot ${ }^{\circledR}$ Competent Cells (Thermo Scientific). The competent cells were transformed based on the manufacturer's instructions. Transformed bacterial colonies containing the recombinant plasmid were grown overnight in $5 \mathrm{~mL}$ LB liquid medium with $100 \mu \mathrm{g} / \mathrm{mL}$ ampicillin at $37^{\circ} \mathrm{C}$ on $225 \mathrm{rpm}$. Plasmid extraction of the cultured colonies was done using the MACHEREY-NAGEL Nucleospin Plasmid kit following the manufacturer's protocol.

\subsection{Sequencing and sequence analysis}

Sanger sequencing was carried out at the GENEWIZ Genomics platform. All sequencing reactions were performed directly on PCR products except for the ITS clones of the three 


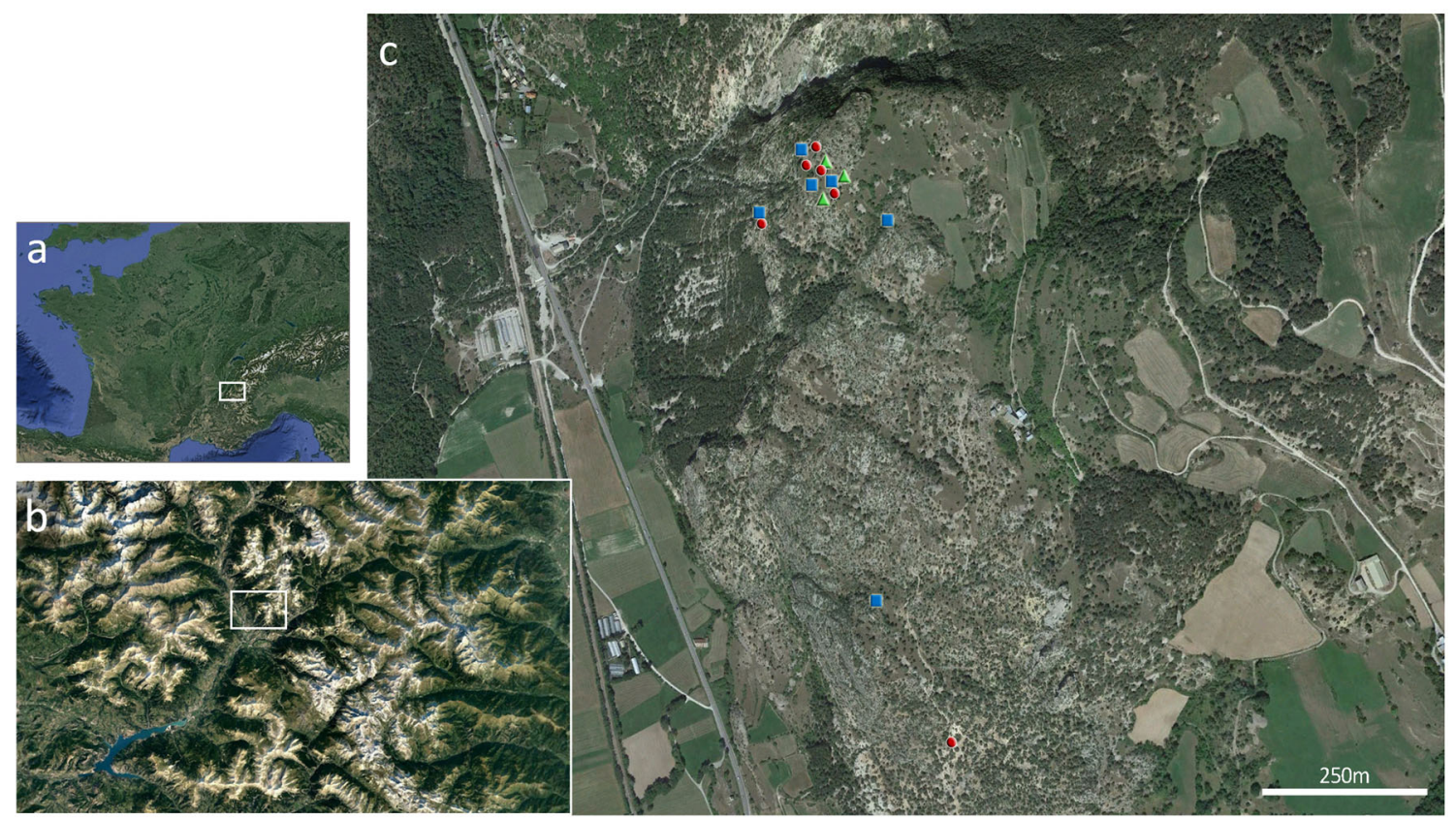

Fig. 2 a, b Studied area at Saint Crépin forest in the department of "Hautes-Alpes" in the South of France. c Locations of the sub-sampling individuals at Saint Crépin, J. thurifera individuals represented by red

putative hybrids for which four clones of each individual were sequenced using M13 universal primers.

All sequencing reactions were performed on the forward and reverse directions. Consensus sequence construction and alignments were conducted under BioEdit software v7.2.6 using the global alignment algorithm.

The corresponding accession number of each studied sequence deposit in NCBI genebank is available in Table 5 in Annex 2.

\subsection{AFLP analysis}

The AFLP experiment was conducted according to Vos et al. (1995) with slight modifications. About 200 ng genomic DNA of each sampled individual was used for digestion and ligation. After pre-amplifications, two different primer combinations were used for the PCR selective amplifications. Adaptors and primers used for the AFLP study are given in Table 6 in Annex 2. Each forward primer used for the selective amplification step was labeled with 6-FAM modification at the $5^{\prime}$ extremity to allow fragment detection on the capillary sequencer (Applied Biosystems ${ }^{\circledR}$ 3730XL). AFLP migration profiles were analyzed using GeneMapper v.5 (Thermo Fisher Scientific) with the GS500 ( -250$)$ LIZ control to scale for fragment size. Fragment selection was based on the calculation of the Bonin error rate (Bonin et al. 2004) using repetitions of control samples. All fragments that had an error $>0 \%$ were discarded.

The data were analyzed using AFLP-SURV v1.0 (Vekemans 2002) to estimate the within (percentage of the circles, $J$. sabina individuals in blue rectangles, and their putative hybrids represented by green triangles

polymorphic locus (PLP)) and between (Fst) species genetic diversity. Allelic frequencies were computed on the basis of Hardy-Weinberg genotypic proportions expectations. The population genetic structure was analyzed using the population genetic model-based Bayesian clustering method implemented in STRUCTURE software v. 2.3.4. The estimated best value of $K$ was determined by using $\Delta K$ statistics (Evanno et al. 2005) implemented on the web site STRUCTURE HARVESTER (http://taylor0.biology.ucla.edu/ structureHarvester/). CLUMPP 1.1.2 (Jakobsson and Rosenberg 2007) was used in order to both homogenize label switching between runs and identify the possibility of multiple clustering solutions (due to multimodality in posterior probability distributions). Then, plots of individual genomic admixtures within inferred genetic clusters were built using STRUCTURE PLOT (http://omicsspeaks.com/strplot2/) (AFLP analysis was detailed in Annex 1).

AFLP raw data are available in Farhat et al. (2020) (https:// doi.org/10.5061/dryad.h44j0zpgk).

\subsection{Pollen analysis}

Pollen staining according to Alexander (1969) was applied on pollen sampled from 10 male cones of each $J$. thurifera tree (JT2, JT3, JT9), from 5 male cones of each J. sabina shrub (JS13, JS22, JS33), and from 10 male cones of each putative hybrid (JTS14 and JTS19). Alexander stain was used in this study only as a way to ensure pollen hydration and not for the test of viability. Pollen grains were examined using a Zeiss Axiophot microscope and 
photographed using a highly sensitive CCD camera (RETIGA 200R, Princeton Instruments, Evry, France) and image analyzer (Metavue, Evry, France).

Around 300 pollen/individual were surveyed for their morphology and classified as normal or abnormal. Those classified as abnormal were collapsed, emptied, and aborted pollen grains. Owing to the spheroidal form of Juniperus pollen grains, with one aperture, only the diameter of the pollen grains was measured to determine their sizes. Diameters of around 100 pollen/cone for each studied individual were measured using the software ImageJ. One way ANOVA and Kruskal Wallis tests were carried out to test pollen size differences among $J$. sabina and $J$. thurifera.

The distribution of pollen size within each sample of $J$. sabina and $J$. thurifera trees as well as for JTS14 and JTS19 were used to assess the frequency of large pollen grains that may be considered as outliers relatively to a normal distribution. Because, the pollen size was continuously distributed, the following approach was used. First, the mean and standard deviation were estimated for each of the four observed distributions. Then, under the hypothesis of the normal distribution, a $1 \%$ threshold was used to identify pollen grains having a size bigger than expected. Finally, for each of the four analyzed pollen samples, the number of outlier pollen grains detected was compared with the expected one under the hypothesis of normal distribution at the $1 \%$ threshold by using a chi-square test ( $1 \mathrm{ddl})$.

Pollen size and morphology were used as criteria to assess the regularity of meiosis in the potential hybrids and their parental taxa.

\section{Results}

\subsection{Genome size estimation of the parental species and their putative hybrids}

The nuclear DNA content (2C value) of $J$. thurifera and $J$. sabina was $45.83 \mathrm{pg}(\sigma=1.04 \mathrm{pg})$ and $23.25 \mathrm{pg}(\sigma=$ $0.25 \mathrm{pg}$ ), respectively (Table 1 ). Regarding the putative hybrid individuals, the 2C DNA values were very close to each other with $34.08 \mathrm{pg}, 34.63 \mathrm{pg}$, and $35.35 \mathrm{pg}$ for JTS8, JTS14, and JTS19, respectively, showing an intermediate genome size between $J$. sabina and $J$. thurifera (Table 1; Fig. 3).

\subsection{Genetic differentiation of parental species and putative hybrids based on ITS and cpDNA sequences}

No intra-specific polymorphism was detected in the chloroplast sequences studied within J. sabina and within $J$. thurifera. Chloroplast regions displayed a high number of fixed differences between the two species. However, the rate

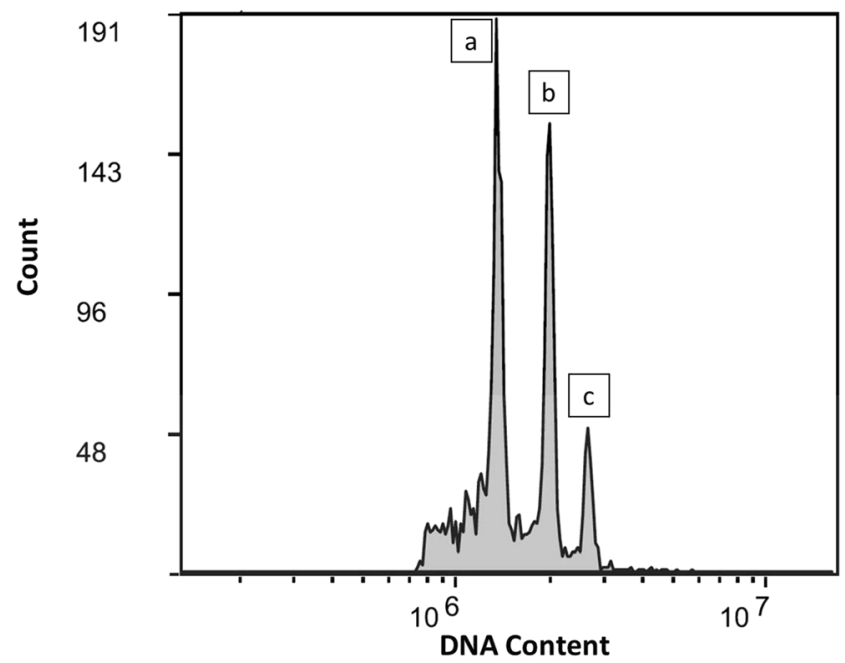

Fig. 3 Distribution of fluorescence intensity representing the DNA content on x-axis of $J$. sabina (a), the putative hybrid (b), and $J$. thurifera (c). The leaves of the three individuals belonging to J. sabina (JS13), J. thurifera (JT5), and the putative hybrid JTS14 were chopped simultaneously without the internal standard plant. Each peak corresponds to one of three ploidy level: $2 n=2 x$ (a), $2 n=3 x$ (b), and $2 n=4 x(\mathrm{c})$

of nucleotide divergence between $J$. sabina and $J$. thurifera varied according to the chloroplast region (petN/psbM; $\operatorname{trnL} / \operatorname{trnF} ; \operatorname{trnS} / \operatorname{trnG} ; \operatorname{trnD} / \operatorname{trnT}$ ). All putative hybrids showed the same sequences as $J$. thurifera for the four chloroplast regions (Table 2).

Concerning the ITS region, 1008 bp were successfully sequenced. Very few intra-specific polymorphisms were detected (4 SNPs within J. sabina and 2 SNPs within J. thurifera). The ITS studied sequences displayed fixed differences between these two species: 13 SNPs and 3 indels. Each putative hybrid showed two haplotypes that correspond to nonrecombinant haplotypes from $J$. sabina and $J$. thurifera (Table 3).

\subsection{Interspecific genetic admixture revealed by AFLP markers}

In total, 147 polymorphic loci remained after the process of peak selection. Only one individual was discarded from the analysis because of its unreadable peak profile. A high polymorphism level was found for AFLP markers at Saint Crépin for both $J$. sabina $(\mathrm{PLP}=55.1 \%)$ and $J$. thurifera $(\mathrm{PLP}=$ $82.31 \%$ ). The genetic differentiation between the two species was relatively high, as expected for two different species $\left(F\right.$ st $\left.=0.17, p<10^{-4}\right)$ despite the fact that only one locus was fixed for alternative alleles. A unique population genetic pattern with two genetic clusters was inferred to be the best solution that fitted the observed data on the basis of the Bayesian clustering analysis (Fig. 7 in Annex 2). 
Table 2 Molecular polymorphism observed between J. sabina, J. thurifera and the putative hybrids for the chloroplast sequences (petN/psbM, trnD/ $\operatorname{trnT}, \operatorname{trnL} / \operatorname{trnF}, \operatorname{trnS} / \operatorname{trnG}$ )

\begin{tabular}{|c|c|c|c|c|c|}
\hline Chloroplast region & Sequence length (bp) & $\begin{array}{l}\text { Loci (position in bp within } \\
\text { the amplified sequence) }\end{array}$ & J. sabina & J. thurifera & Putative hybrids \\
\hline \multirow[t]{17}{*}{$\mathrm{petN} / \mathrm{psbM}$} & \multirow[t]{17}{*}{863} & $148->153$ & TGATAA & - & - \\
\hline & & 155 & $\mathrm{G}$ & A & A \\
\hline & & $196->205$ & - & ATTCATTAAT & ATTCATTAAT \\
\hline & & 206 & $\mathrm{G}$ & $\mathrm{T}$ & $\mathrm{T}$ \\
\hline & & 279 & $\mathrm{~T}$ & A & A \\
\hline & & 280 & - & $\mathrm{T}$ & $\mathrm{T}$ \\
\hline & & $293-294$ & TA & AT & AT \\
\hline & & 324 & $\mathrm{~T}$ & $\mathrm{C}$ & $\mathrm{C}$ \\
\hline & & 347 & $\mathrm{~T}$ & $\mathrm{C}$ & $\mathrm{C}$ \\
\hline & & $352->360$ & - & AATGAACTA & AATGAACTA \\
\hline & & 439 & $\mathrm{~T}$ & $\mathrm{G}$ & $\mathrm{G}$ \\
\hline & & $526->540$ & TTTATTTACAATCAA & - & - \\
\hline & & 574 & $\mathrm{G}$ & A & A \\
\hline & & $593->596$ & - & ACGA & ACGA \\
\hline & & 597 & A & G & $\mathrm{G}$ \\
\hline & & $667 \rightarrow 675$ & TTTTTTTCT & - & - \\
\hline & & $688->694$ & TAATTAG & - & - \\
\hline \multirow[t]{10}{*}{$\operatorname{trnD} / \operatorname{trnT}$} & \multirow[t]{10}{*}{620} & 33 & $\mathrm{C}$ & $\mathrm{T}$ & $\mathrm{T}$ \\
\hline & & 36 & A & - & - \\
\hline & & 100 & A & $\mathrm{C}$ & $\mathrm{C}$ \\
\hline & & 124 & G & $\mathrm{C}$ & $\mathrm{C}$ \\
\hline & & 134 & - & A & A \\
\hline & & 170 & $\mathrm{C}$ & $\mathrm{T}$ & $\mathrm{T}$ \\
\hline & & 320 & $\mathrm{~A}$ & - & - \\
\hline & & 550 & $\mathrm{~A}$ & $\mathrm{G}$ & G \\
\hline & & 556 & $\mathrm{C}$ & $\mathrm{T}$ & $\mathrm{T}$ \\
\hline & & 593 & $\mathrm{C}$ & G & $\mathrm{G}$ \\
\hline \multirow[t]{5}{*}{$\operatorname{trnL} / \operatorname{trnF}$} & \multirow[t]{5}{*}{660} & 4 & A & G & G \\
\hline & & 345 & G & $\mathrm{C}$ & $\mathrm{C}$ \\
\hline & & $444->463$ & CTGTA...AAA & - & - \\
\hline & & 474 & $\mathrm{~T}$ & - & - \\
\hline & & 475 & $\mathrm{~A}$ & - & - \\
\hline \multirow[t]{7}{*}{$\operatorname{trnS} / \operatorname{trnG}$} & \multirow[t]{7}{*}{785} & 9 & $\mathrm{~T}$ & $\mathrm{C}$ & $\mathrm{C}$ \\
\hline & & 52 & $\mathrm{~T}$ & - & - \\
\hline & & 97 & $\mathrm{~T}$ & $\mathrm{C}$ & $\mathrm{C}$ \\
\hline & & $272->289$ & - & АТT...TCT & АTТ...ТСТ \\
\hline & & 301 & A & $\mathrm{C}$ & $\mathrm{C}$ \\
\hline & & 613 & A & $\mathrm{G}$ & $\mathrm{G}$ \\
\hline & & 753 & $\mathrm{~T}$ & $\mathrm{C}$ & $\mathrm{C}$ \\
\hline
\end{tabular}


Table 3 Polymorphic sites observed within ITS sequences between $J$. sabina, J. thurifera and haplotypes found in the putative hybrids

\begin{tabular}{|c|c|c|c|c|c|c|c|c|c|c|c|c|c|c|c|c|}
\hline \multirow[t]{2}{*}{ Taxa } & \multicolumn{16}{|c|}{ Site within the ITS sequence } \\
\hline & 75 & 126 & 134 & 247 & 257 & 262 & 323 & 500 & 508 & 509 & 533 & 657 & 679 & 699 & 703 & 893 \\
\hline J. sabina & $\mathrm{C}$ & $\mathrm{C}$ & $\mathrm{T}$ & $\mathrm{T}$ & $\mathrm{A}$ & $\mathrm{C}$ & $\mathrm{T}$ & A & - & - & $\mathrm{C}$ & $\mathrm{G}$ & $\mathrm{C}$ & G & - & A \\
\hline J. thurifera & $\mathrm{T}$ & A & $\mathrm{C}$ & $\mathrm{C}$ & $\mathrm{G}$ & $\mathrm{T}$ & $\mathrm{C}$ & $\mathrm{C}$ & $\mathrm{T}$ & G & $\mathrm{T}$ & $\mathrm{T}$ & $\mathrm{T}$ & $\mathrm{A}$ & A & $\mathrm{C}$ \\
\hline Putative hybrids JTS8, JTS14 and JTS19 Haplotype 1 & $\mathrm{C}$ & $\mathrm{C}$ & $\mathrm{T}$ & $\mathrm{T}$ & A & $\mathrm{C}$ & $\mathrm{T}$ & A & - & - & $\mathrm{C}$ & G & $\mathrm{C}$ & G & - & A \\
\hline Putative hybrids JTS8, JTS14 and JTS19 Haplotype 2 & $\mathrm{~T}$ & A & $\mathrm{C}$ & $\mathrm{C}$ & G & $\mathrm{T}$ & $\mathrm{C}$ & $\mathrm{C}$ & $\mathrm{T}$ & $\mathrm{G}$ & $\mathrm{T}$ & $\mathrm{T}$ & $\mathrm{T}$ & A & A & $\mathrm{C}$ \\
\hline
\end{tabular}

The distribution of the dominant phenotype (fragment presence) frequency differences between $J$. sabina and $J$. thurifera was centered close to zero $($ mean $=-0.03$; median $=-0.08$; Fig. 8 in Annex 2) with a very slight bias towards a majority of locus having the dominant phenotype in J. thurifera. Inferences on individual genomic admixtures were therefore expected to be only slightly influenced (with an advantage to $J$. thurifera assignment), on average, by dominance effects. The genomic individual assignment pattern showed that the two inferred genetic clusters corresponded, as expected for distinct species, to J. sabina and J. thurifera (Fig. 4). However, the genomes of a few $J$. thurifera individuals were clearly admixed whereas admixture levels were nearly null for all $J$. sabina individuals. Besides, the three putative triploid hybrids were inferred to have an admixed genome. The mean proportion of their genome assigned to "sabina" genetic cluster was $11.7 \%$ for JTS8, $28.1 \%$ for JTS14, and $42.0 \%$ for JTS19. It was noticeable that two other individuals showed a clear admixed genomic pattern: JT39 and JT28 displayed $18.4 \%$ and $14.0 \%$ of their genome assigned to "sabina" genetic cluster, respectively. These two individuals were shown to be tetraploid, their morphology was "thurifera" like (Fig. 1) and they had $J$. thurifera haplotypes for both chloroplast and ITS sequences (data not shown).

\subsection{Pollen characterization of Juniperus taxa}

Pollen grains of juniper studied taxa are spherical and do not hold air sacs (Fig. 5). Morphological abnormalities of pollen grains have been observed in individuals of $J$. sabina and $J$. thurifera but at relatively low frequencies ca. $9.5 \%$ and ca. $0.9 \%$, respectively. In contrast, pollen grain abnormalities were found more frequently in the two potential male hybrids: JTS14 (ca. 35.3\%) (Fig. 5d) and JTS19 (32.5\%).

A total of 1712 pollen grains was measured for $J$. sabina showing that the pollen sizes ranged from 13.6 to $35.6 \mu \mathrm{m}$ with a mean of $21.3 \mu \mathrm{m}(\sigma=2.3$ $\mu \mathrm{m}$ ) (Fig. 6). Regarding $J$. thurifera, the size of 3171 pollen grains was measured and the pollen sizes ranged from 20 to $45.5 \mu \mathrm{m}$. The mean pollen size was $27.8 \mu \mathrm{m}(\sigma=3.2 \mu \mathrm{m})$ (Fig. 6). Both ANOVA $(F=$ 48193, df $=1, p<2 \mathrm{e}-16$ ) and Kruskal Wallis (chisquared $=2924, \mathrm{df}=1, p$ value $<2.2 \mathrm{e}-16)$ tests showed that the tetraploid species, J. thurifera, produced significantly bigger pollen grains (1.31 bigger in mean) than the diploid J. sabina. The pollen size distribution was clearly Gaussian for J. sabina but slightly skewed for $J$. thurifera due to large pollen grains (Fig. 9 in Annex 2). Indeed, the frequency of pollen grains showing large-diameter values in $J$. thurifera was approximately three times higher than expected (at $1 \%$ threshold) under a normal distribution $\left(2.9 \% ; \chi^{2}=\right.$ 113,$65 ; 1 \mathrm{ddl} ; p$ value $<10^{-7}$ ). Contrarily, the proportion of large pollen observed in J. sabina corresponded to the expectation under a normal distribution and at the $1 \%$ threshold (ca. $0.9 \% ; \chi^{2}=0.82 ; 1$ ddl; not significant (NS)) (Figs. 5 and 6).

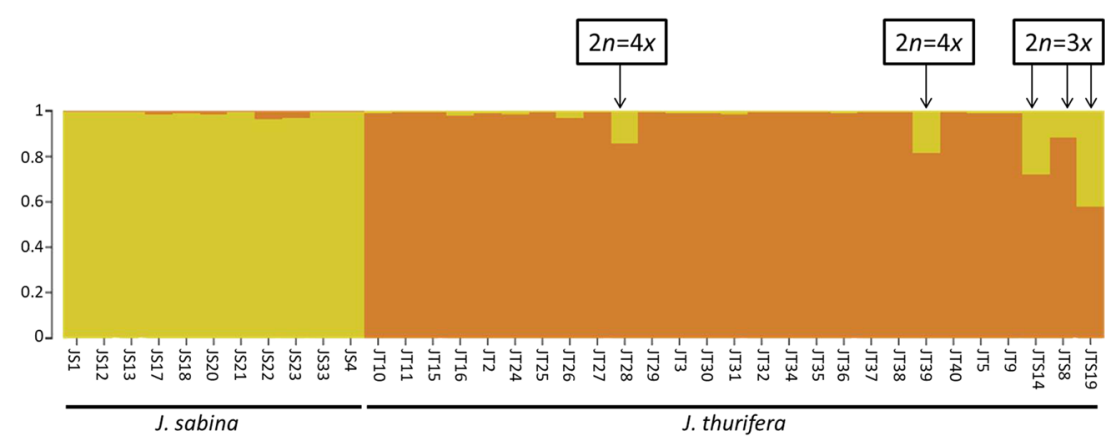

Fig. 4 Individual genomic assignment to each of the two genetic clusters $(K=2)$. JS stands for $J$. sabina and JT stands for J. thurifera. JTS is used to name the three putative triploid hybrids. Black arrows point, from left to right, to the two tetraploid individuals with high genomic admixture between "thurifera" and "sabina" genetic clusters and to the three putative triploid hybrids 

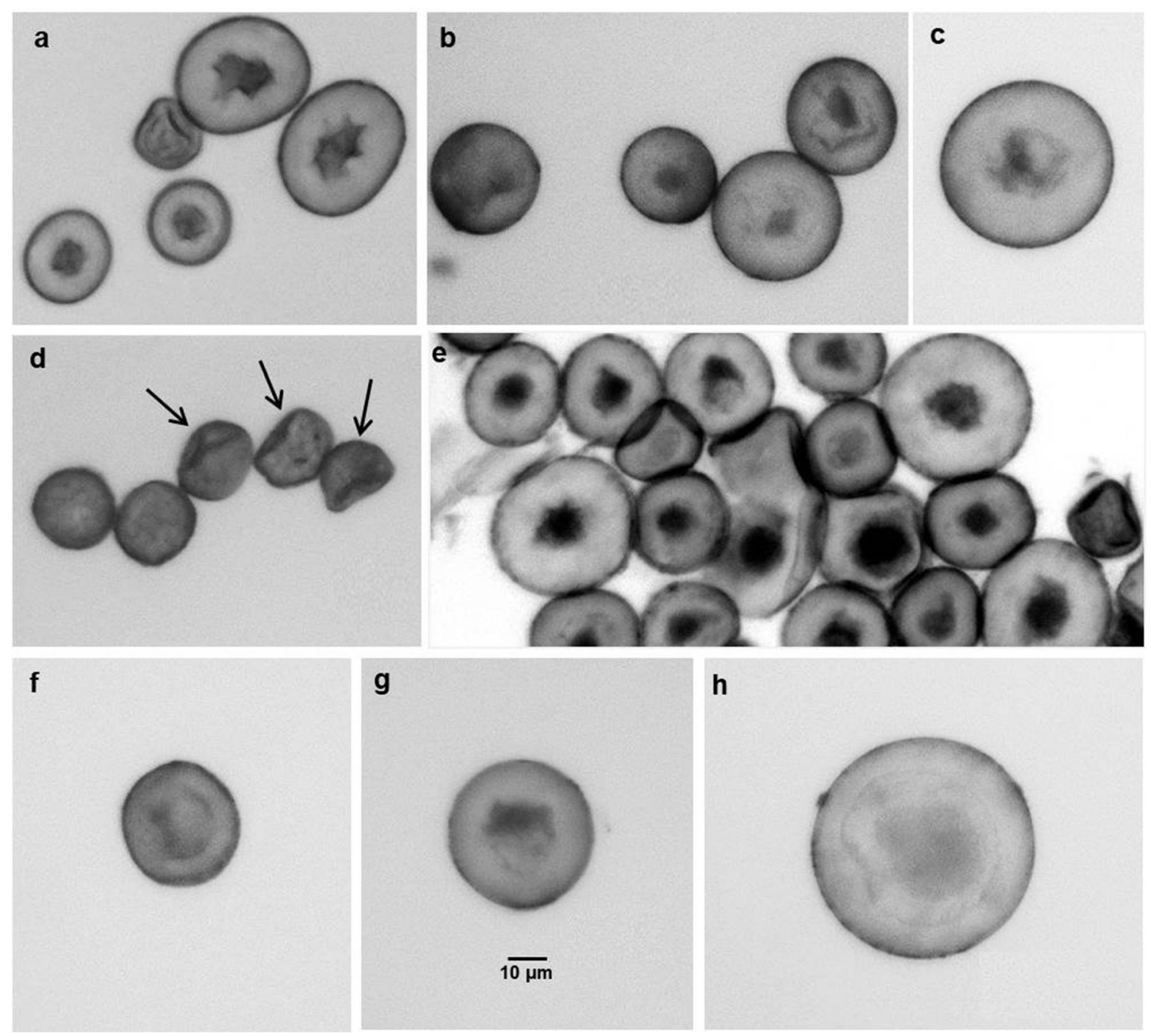

Fig. 5 Microphotographs of pollen grains (all pollen pictures are on the same scale size). a $J$. sabina pollen grains showing variability in pollen sizes. b $J$ thurifera pollen grains showing size variation representative of most pollen from this species. $\mathbf{c} J$. thurifera pollen grain showing a large size, considered as possibly unreduced. d Aborted pollen grains (arrows) produced by the potential hybrid JTS14. e JTS14 pollen grains showing various sizes. $\mathbf{f}, \mathbf{g}$, and $\mathbf{h}$ show JTS19 pollen grains of different sizes. $\mathbf{h}$ Pollen grain with a large size and considered as possibly unreduced
For the two potential male hybrids, JTS14 and JTS19, 686 and 928 pollen grains were measured, respectively. For JTS14, pollen size varied from 17 to $44 \mu \mathrm{m}$ (Fig. 6), the mean size was $25.4 \mu \mathrm{m}(\sigma=3.2 \mu \mathrm{m})$. The mean pollen size was therefore intermediate between those observed in the two parental species. JTS14 did not produce a significant frequency of pollen grains with large sizes at the $1 \%$ threshold $\left(1.6 \% ; \chi^{2}\right.$ $=2.31 ; 1 \mathrm{ddl} ; \mathrm{NS})$. For JTS19, pollen size varied from 17.8 to $57 \mu \mathrm{m}$ with a mean pollen size of $27 \mu \mathrm{m}(\sigma=5.5 \mu \mathrm{m})$ (Fig. 6), close to the value observed in J. thurifera. JTS19 presented a larger variance in pollen sizes than JTS14 and the two parental species (Fig. 9 in Annex 2). This is explained by the pollen size distribution that was clearly skewed in favor of large pollen (ca. 4.9\%; $\chi^{2}=145.4 ; 1 \mathrm{ddl} ; \mathrm{p}<10^{-7}$ ) (Fig. 6). Pollen size measurements are summarized in Table 7 in Annex 2.

\section{Discussion}

\subsection{Genome size and ploidy level diversity in the hybrid zone}

In this study, estimated genome size showed that $J$. thurifera (45.83 pg, $\sigma=1.04 \mathrm{pg}$ ) studied trees had genome size approximately 2 fold bigger than the studied shrubs of J. sabina ( 23.25 $\mathrm{pg}, \sigma=0.25 \mathrm{pg}$ ). This suggests that studied individuals of $J$ thurifera and J. sabina were tetraploid and diploid, respectively. These results broadly agree with previous studies of genome size and chromosome number for other populations of those two species reporting $J$. sabina as diploid $(2 n=2 x=$ 22 with ca. $23 \mathrm{pg}$ ) except for the tetraploid J. sabina var. balkanensis R. P. Adams and A. Tashev (Farhat et al. 2019a, $2019 b)$ and $J$. thurifera as tetraploid $(2 n=4 x=44$ and ca. 41.2 pg/2C) (Romo et al. 2013; Vallès et al. 2015). The estimated 
Fig. 6 Box plot showing pollen grain size variability of $J$. sabina $(N=3$ individuals and 1712 pollen grains), J. thurifera $(N=3$ individuals and 3171 pollen grains) and the two male putative triploid hybrids JTS14 (686 pollen grains) and JTS19 (928 pollen grains)

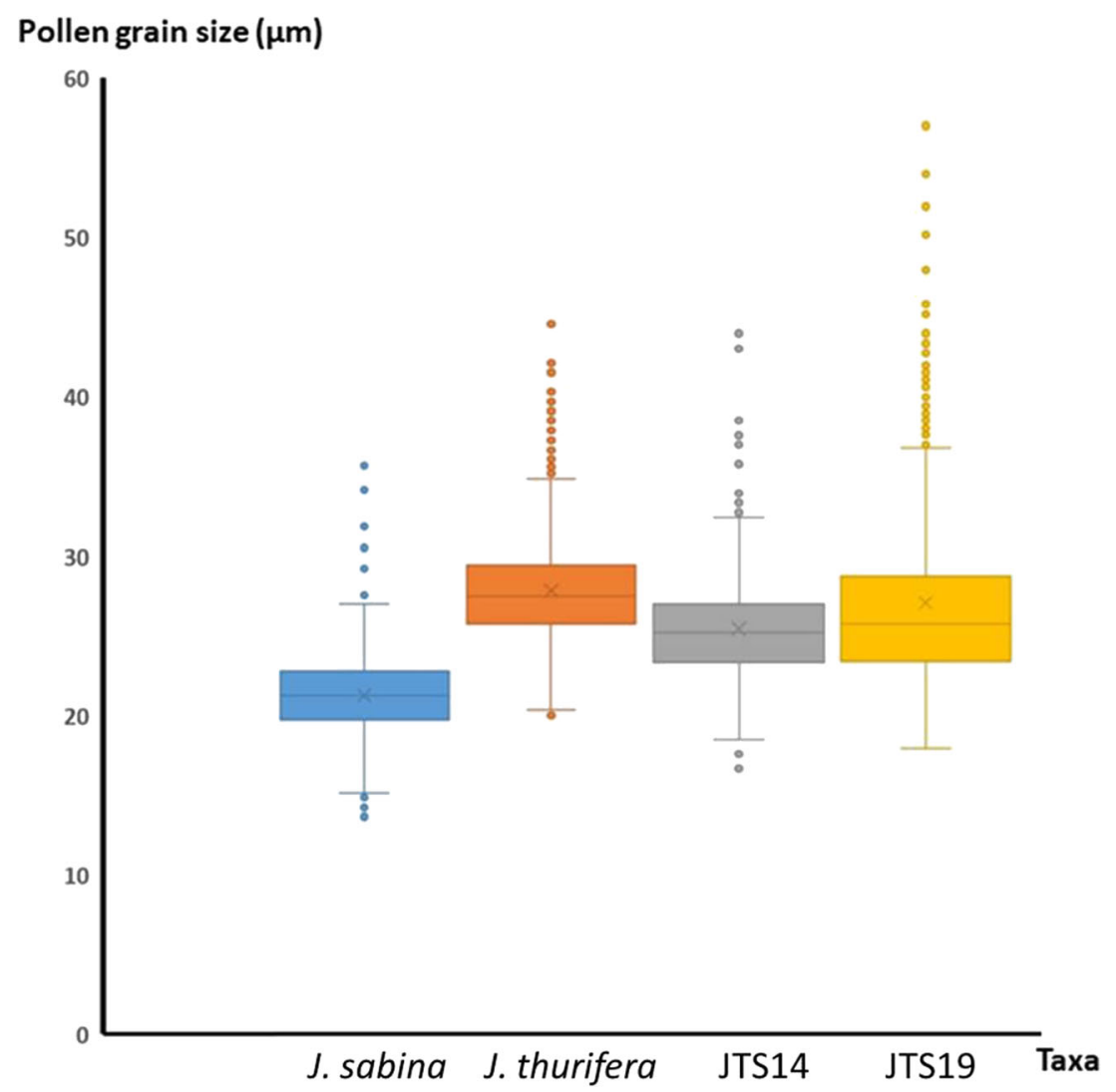

genome sizes of the three putative hybrids were intermediate (mean 2C DNA content: $34.69 \mathrm{pg}, \sigma=0.64 \mathrm{pg}$ ) between those of the potential parents. It was demonstrated in Juniperus that genome size could be used as a reliable proxy for the ploidy level determination (Farhat et al. 2019a). Moreover, three classes of genome sizes were shown to correspond to three ploidy levels (diploidy, tetraploidy, and hexaploidy) (Farhat et al. 2019a). Based on these classes, the genome size estimated for the three putative hybrid individuals showed that they are most likely triploids. In this genus, few sporadic triploid cytotypes have already been found in some ornamental cultivars (Adams et al. 2019; Hall et al. 1973). However, this study brought the first evidence for natural triploid in the Juniperus genus and generally among all conifers found in the wild.

\subsection{Hybridization patterns of Juniperus taxa in the population of Saint Crépin}

It has been commonly assumed that hybridization between species with different ploidy levels is very limited (Coyne and Orr 2004). Nevertheless, if hybridization occurs, the establishment of those hybrids must overcome severe postzygotic barriers such as unviability and sterility (Baack et al. 2015; Husband and Sabara 2004), particularly in triploids and odd ploidy levels.
Our results on ITS nuclear sequences, showing that the three morphologically atypical individuals (JTS8, JTS14, and JTS19) displayed two ITS haplotypes: one specific to J. sabina and the other specific to $J$. thurifera, proved that these three individuals are hybrids between these two species. This last conclusion was also strongly supported by AFLP markers that clearly showed the admixture genetic nature of these three hybrids. Obviously, estimated values of individual genomic admixture must be taken with great caution since estimation uncertainty is related to several factors: effect of locus sampling, estimation of allele frequencies within true genetic clusters, non-repeatability of detected peaks (since not all individuals were repeated in the experiment), dominance effects (although we showed in our case that dominance effects across locus were almost evenly distributed between the two species), and possible violations of assumptions underlying the genetic model used by STRUCTURE, especially the "no linkage disequilibrium" hypothesis. However, it was noticeable that the proportion of $J$. sabina genome, inferred from AFLP data, into two of the three triploid hybrids (JTS14 and JTS19) was relatively close to $33.3 \%$. This value is expected in the case of a first-generation triploid hybrid and of an identical frequencies distribution of dominant phenotypes between the two species. Despite that JTS8 
displayed only $11.8 \%$ of its genome assigned to "sabina" genetic cluster, it still may be a first-generation triploid hybrid. In that case, JTS 8 had inherited by chance a majority of loci for which the dominant allele was inherited from $J$. thurifera parent, a situation that may bias the genomic assignment to "thurifera" cluster. In addition to these three triploid hybrids, we found two tetraploid trees (JT28 and JT39) displaying a large portion $(>10 \%)$ of their genome assigned to "sabina" cluster. This result suggested that these two individuals could be backcrossed progenies.

In conifers and more particularly in the Cupressaceae family, the chloroplast has been shown mainly to be paternally inherited (Adams 2019; Hipkins et al. 1994; Neale and Sederoff 1989; Sakaguchi et al. 2014). The fact that the three triploid hybrids had the same chloroplast DNA sequences of $J$. thurifera argues in favor that this species was the paternal parent, and therefore, J. sabina was the maternal parent. However, the paternal inheritance of the chloroplast genome in Juniperus should be checked in the near future to confirm this hypothesis.

Finally, the combination of genome size with molecular data supports that JTS14 and JTS19 at least, and possibly JTS8, are first-generation hybrids produced through the fertilization of a reduced female gamete $(n=1 x=11)$ of the diploid $J$. sabina by reduced pollen $(n=2 x=22)$ of the tetraploid J. thurifera.

Ancient hybridization between ancestral lineages of those two species was previously suggested leading to the tetraploid variety J. sabina var. balkanensis (Adams et al. 2016; Farhat et al. 2019b). Currently, J. thurifera has a West-Mediterranean range and is absent from the Balkans where $J$. sabina var. balkanensis mostly exists (Adams et al. 2018). Also, other putative hybrids displaying intermediate morphology between those two species were described in one sympatric area from Spain (Aparicio and Uribe-Echebarría 2009). These observations together with our results suggest that reproductive barriers between $J$. sabina and $J$. thurifera are incomplete, allowing interspecific hybridization, and even genetic introgression through further backcrossing, to occur. However, the question of whether gene flow between these two species at Saint Crépin is rare or has occurred regularly in the past is still opened. Moreover, overlapping in their flowering period is essential for gene flow occurrence. Unfortunately, no data is yet available on this issue in the French Alps. Investigations on the phenology of both species across years at Saint Crépin and other places of sympatry will enlighten this question.

\subsection{Pollen production of the parental species and their triploid hybrids}

In general, a strong positive correlation has been observed between pollen size and both genome size and ploidy level (Katsiotis and Forsberg 1995; Srisuwan et al. 2019). This was also the case in our study where the mean pollen diameter of the tetraploid $J$. thurifera was shown to be 1.3 fold bigger than the mean pollen diameter of the diploid J. sabina.

In this study, $J$. thurifera displayed pollen grains with a large diameter at significant frequencies (ca. 2.9\%) which could witness the production of unreduced gametes in this tetraploid species. This was not the case for J. sabina. However, in this study, only three trees were included for this species. In conifers, unreduced gametes have been found only in the diploid Cupressus dupreziana A. Camus with a pollen diameter of ca. $38 \mu \mathrm{m}$ (Pichot and El Maâtaoui 2000). Conversely, in angiosperms, the production of unreduced gametes has been noticed to be frequent and classified as a major mechanism leading to polyploidy (Otto and Whitton 2000; Ramsey and Schemske 1998). Interestingly, the potential production of unreduced gametes has been suggested to contribute to the high rate of polyploidy previously found in Juniperus (ca. 15\%, the highest rate within conifers) (Farhat et al. 2019a). However, further work must be conducted to estimate more reliably the eventual presence of unreduced gametes in Juniperus species by measuring the genome size of pollen grains.

Yet, the large variance observed in pollen sizes of the hybrid JTS19, as well as the observation of pollen grains with a morphological abnormality in JTS14 and JTS19 (ca.35.3\% and $32.5 \%$, respectively), might reflect the irregular meiosis of these hybrids. Indeed, meiotic irregularities are well documented in interspecific hybrids, especially in those with odd ploidy levels such as triploids, which are often considered as sterile (Comai 2005; Giles 1941; Karlsdóttir et al. 2008). Interestingly, studied individuals of both parental species showed a relatively low frequency of morphological abnormal pollen grains, especially for the tetraploid J. thurifera (ca. $0.9 \%$ ). In general, meiotic irregularities have been reported in polyploid individuals (Comai 2005; Van de Peer et al. 2017). However, the very low frequency of abnormal pollen grains found in this study for the tetraploid $J$. thurifera suggested that meiosis was regular and that this species may have undergone diploidization. This was consistent with the hypothesis that $J$. thurifera is considered as a paleopolyploid based on cytological approaches (Vallès et al. 2015). Further work must be conducted to confirm the production of partially reduced and unreduced gametes by the triploid hybrids using flow cytometry. Also, more research should be conducted to assess the viability of pollens produced by the hybrids and the parental species. 


\section{Conclusion}

This study reported the first evidence of triploid hybrids between two junipers, J. sabina $(2 n=2 x)$ and $J$. thurifera $(2 n=4 x)$, that grow in sympatry at Saint Crépin forest of the French Alps. Also, it suggested that genetic introgression through backcrosses between triploid hybrids and parental species may have occurred. The considerable variation found in pollen size of studied individuals belonging to $J$. thurifera would propose their possibility for unreduced gametes production. The two male triploid hybrids showed evidence of abnormal pollen suggesting meiosis irregularities.

Additional investigations on genome size and genetic diversity of a larger sample of individuals in Saint Crépin forest and in other locations, where the two species have been reported to be in sympatry, are needed to reach a better insight into the existence of recurrent genetic introgressions. Further analysis of the phenology of $J$. sabina and $J$. thurifera in Saint Crépin is needed to strengthen assessments of opportunities for gene flow occurrence. This study opens new avenues towards studying the ecological and genetic consequences of genetic introgressions that might occur between those two species.

Acknowledgment We thank Mr. Daniel Bénéfice and Mr. Bertrand Lienard from the National Alpine Botanical Conservatory, Mr. Frédéric Marais from the Forests National office (ONF), and Prof. Thierry Gauquelin from Aix-Marseille University for their kind help in the fieldwork. The authors also thank Dr. Mickaël Bourge and Mr. Nicolas Valentin from "Plateforme de Cytométrie, CNRS - I2BC, Gif sur Yvette," for the expert assistance in flow cytometry. We thank GENTYANE Platform at the INRA Research Unit "Génétique, Diversité et Ecophysiologie des Céréales" (UMR 1095), ClermontFerrand (France), for AFLP genotyping on ABI sequencer.

Contribution of the co-authors TR and SS-Y designed the study; PF, TR, and LG did the plant sampling; PF and SS-Y carried out the pollen size and flow cytometry measurements; PF, NT, and TR carried out the sequence analysis; TR, NT, and MA carried out the AFLP experiment and analysis; PF wrote a first draft of the manuscript that was further critically reviewed by MBK, RA, NT, SS-Y, and TR.

Funding This work was supported by the National Council for Scientific Research-Lebanon [CNRS-FS90], the Saint-Joseph University Research Council (CR-USJ) [FS-111], the International Relations of Paris-Saclay University, and the Doctoral School "Sciences du Végétal: du gène à l'écosystème" of Paris Sud University.

Data availability The sequence data generated during the current study are available on NCBI genebank and accession numbers are available in Table 5. The AFLP data are available on the Dryad platform in Farhat et al. (2020) https://doi.org/10.5061/dryad.h44j0zpgk.

\section{Compliance with ethical standards}

Conflict of interest The authors declare that they have no conflict of interest.

\section{פ2 spmeng INRAE}

Statement of informed consent The authors declare that they obtained informed consent from all participants involved in this study.

\section{Annexes}

\section{Annex 1 AFLP detailed peak detection, peak selection, and population genetic analysis}

Eight negative controls were included in the PCR and genotyping steps. Also, seven individuals randomly chosen (five from J. sabina and two from J. thurifera) were repeated three times: two repetitions were done at the extraction stage and kept all along the process, and the third one was included after the digestion-ligation step at PCR and genotyping steps. These controls were dedicated to test fragment detection repeatability.

AFLP migration profiles were analyzed using GeneMapper v.5 (Thermo Fisher Scientific) using the GS500 (- 250) LIZ control to scale for fragment size. Default options were used as the first step for peak selection and phenotype (presence vs absence of detected peak) assignment. Only peaks having a size between 60 and $500 \mathrm{bp}$ were kept for the analysis. Peaks were also checked manually for each individual. Individuals that displayed bad profiles (strong background noise or weak signals) were removed from the analysis. Fragment presences peaks were also checked by eye for each individual.

In order to reduce potential phenotype miscalling, controls were used to select peaks on the basis of their repeatability and reliability as follows:

1. All peaks detected in negative controls were removed.

2. The second step of peak selection was based on the calculation of the Bonin error rate (Bonin et al. 2004) using repetitions of control samples. All peaks that had an error $>0 \%$ were discarded.

3. Locus displaying alternative phenotypes (presence or absence of the detected peak in only one individual among the whole sample (singletons)) were also discarded since this type of variation may be easily obtained because of genotyping error.

Population genetic structure was analyzed using the population genetic model-based Bayesian clustering method implemented in STRUCTURE software v. 2.3.4. The best-fitting structure was searched by varying the number of genetic clusters $(K)$ from 1 to 6 and using 10 independent runs of the MCMC chain. For each run, 70,000 iterations were used for the burn-in period of the MCMC chain, and 120,000 supplementary iterations were used for sampling the posterior probability distribution. The estimated best value of $K$ was determined by using $\Delta K$ statistics (Evanno et al. 2005) implemented on the web site STRUCTURE HARVESTER http://taylor0. 
biology.ucla.edu/structureHarvester/. Then, for the best $K$, 50 independent repetitions of the MCMC chain were run again. Results from the 50 runs were analyzed using CLUMPP 1.1.2 (Jakobsson and Rosenberg 2007).

\section{Annex 2}

Table 4 Primer sequences and PCR annealing temperatures. F: Forward, R: Reverse

\begin{tabular}{lllll}
\hline Primer F & Primer F sequence $\left(5^{\prime} \rightarrow 3^{\prime}\right)$ & Primer R & Primer R sequence $\left(5^{\prime} \rightarrow 3^{\prime}\right)$ & Annealing temperature \\
\hline ITSA & GGAAGGAGAAGTCGTAACAAGG & ITSB & CTTTTCCTCCGCTTATTGATATG & $61^{\circ} \mathrm{C}$ \\
petN & AACGAAGCGAAAATCAATCA & $\operatorname{psbM}$ & AAAGAGAGGGATTCGTATGGA & $57^{\circ} \mathrm{C}$ \\
$\operatorname{trnL}$ & CGAAATCGGTAGACGCTACG & $\operatorname{trnF}$ & ATTTGAACTGGTGACACGAG & $60^{\circ} \mathrm{C}$ \\
$\operatorname{trnS}$ & GCCGCTTTAGTCCACTCAGC & $\operatorname{trnG}$ & GAACGAATCACACTTTTACCAC & $62^{\circ} \mathrm{C}$ \\
$\operatorname{trn} D$ & ACCAATTGAACTACAATCCC & $\operatorname{trnT}$ & CTACCACTGAGTTAAAAGGG & $60^{\circ} \mathrm{C}$ \\
\hline
\end{tabular}

Table 5 Accession numbers of sequences from the four chloroplast (trnD-T, trnL-F, PetN-psbM, and trnS-G) markers and nuclear (ITS) region of the studied trees available on NCBI genebank (seq. acc. number stands for sequence accession number)

\begin{tabular}{|c|c|c|c|c|c|c|}
\hline Species & $\begin{array}{l}\text { Sample } \\
\text { abbreviation }\end{array}$ & $\begin{array}{l}\text { trnD-trnT seq. } \\
\text { acc. number }\end{array}$ & $\begin{array}{l}\text { trnL-trnF seq. } \\
\text { acc. number }\end{array}$ & $\begin{array}{l}\text { PetN-psbM seq. } \\
\text { acc. number }\end{array}$ & $\begin{array}{l}\text { trnS-trnG seq. } \\
\text { acc. number }\end{array}$ & ITS seq. acc. number \\
\hline J. thurifera & JT2 & MN248711 & MN248727 & MT114139 & MN831462 & MT112128 \\
\hline J. thurifera & JT3 & MN248712 & MN248726 & MT114140 & MN831467 & MT112127 \\
\hline J. thurifera & JT5 & MN248713 & MN248731 & MT114141 & MN831464 & MT112129 \\
\hline J. thurifera & JT9 & MN248716 & MN248730 & MT114142 & MN831463 & MT112130 \\
\hline J. thurifera & JT16 & MN248715 & MN248729 & MT114143 & MN831466 & MT112132 \\
\hline J. thurifera & JT39 & MN248714 & MN248728 & MT114144 & MN831465 & MT112131 \\
\hline J. sabina & JS1 & MN248710 & MN248721 & MT114133 & MN831456 & MT112124 \\
\hline J. sabina & JS4 & MN248705 & MN248720 & MT114134 & MN831457 & MT112125 \\
\hline J. sabina & JS13 & MN248706 & MN248722 & MT114135 & MN831458 & MT112121 \\
\hline J. sabina & JS17 & MN248707 & MN248725 & MT114136 & MN831459 & MT112126 \\
\hline J. sabina & JS22 & MN248708 & MN248724 & MT114137 & MN831460 & MT112122 \\
\hline J. sabina & JS33 & MN248709 & MN248723 & MT114138 & MN831461 & MT112123 \\
\hline $\begin{array}{l}\text { J. sabina } \times \\
\quad \text { J. thurifera }\end{array}$ & JTS8 & MN248717 & MN248732 & MT114145 & MN831468 & $\begin{array}{l}\text { MT112136, MT112137, MT112143, } \\
\text { MT112144. }\end{array}$ \\
\hline $\begin{array}{l}\text { J. sabina } \times \\
\text { J. thurifera }\end{array}$ & JTS14 & MN248718 & MN248733 & MT114146 & MN831469 & $\begin{array}{l}\text { MT112134, MT112135, MT112141, } \\
\text { MT112142. }\end{array}$ \\
\hline $\begin{array}{l}\text { J. sabina } \times \\
\text { J. thurifera }\end{array}$ & JTS19 & MN248719 & MN248734 & MT114147 & MN831470 & $\begin{array}{l}\text { MT112133, MT112138, MT112139, } \\
\text { MT112140. }\end{array}$ \\
\hline
\end{tabular}


Table 6 Adapters and primers used for the AFLP experiment

\begin{tabular}{lll}
\hline Name & Step of AFLP experiment & Sequence $\left(5^{\prime} \rightarrow 3^{\prime}\right)$ \\
\hline EcoRI L adapter & Ligation & CTCGTAGACTGCGTACC \\
EcoRI S adapter & Ligation & AATTGGTACGCAGTC \\
MseI L adapter & Ligation & GACGATGAGTCCTGAG \\
MseI S adapter & Ligation & TACTCAGGACTCAT \\
EcoRI primer & Pre-amplification & ACTGCGTACCAATTCA \\
MseI primer & Pre-amplification & GATGAGTCCTGAGTAAC \\
EcoRI primer 1 & Selective amplification (primer combination 1) & ACTGCGTACCAATTCACT \\
MseI primer 1 & Selective amplification (primer combination 1) & GATGAGTCCTGAGTAACTA \\
EcoRI primer 2 & Selective amplification (primer combination 2) & ACTGCGTACCAATTCACG \\
MseI primer 2 & Selective amplification (primer combination 2) & GATGAGTCCTGAGTAACTT \\
\hline
\end{tabular}

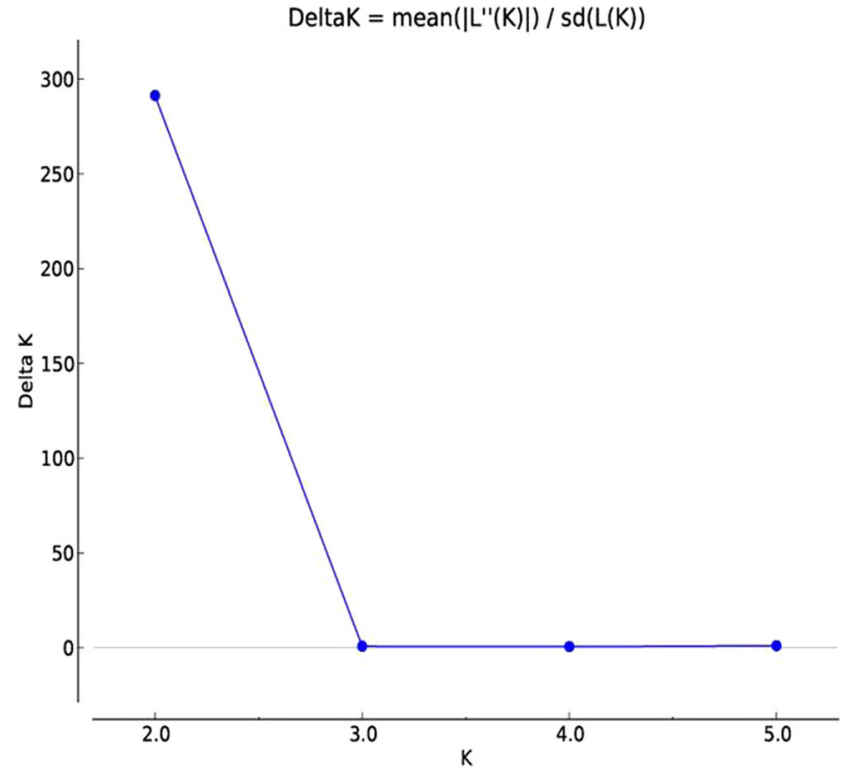

Fig. 7 Results of $\Delta K$ Evanno's test showing two genetic clusters as the best solution $(K=2)$

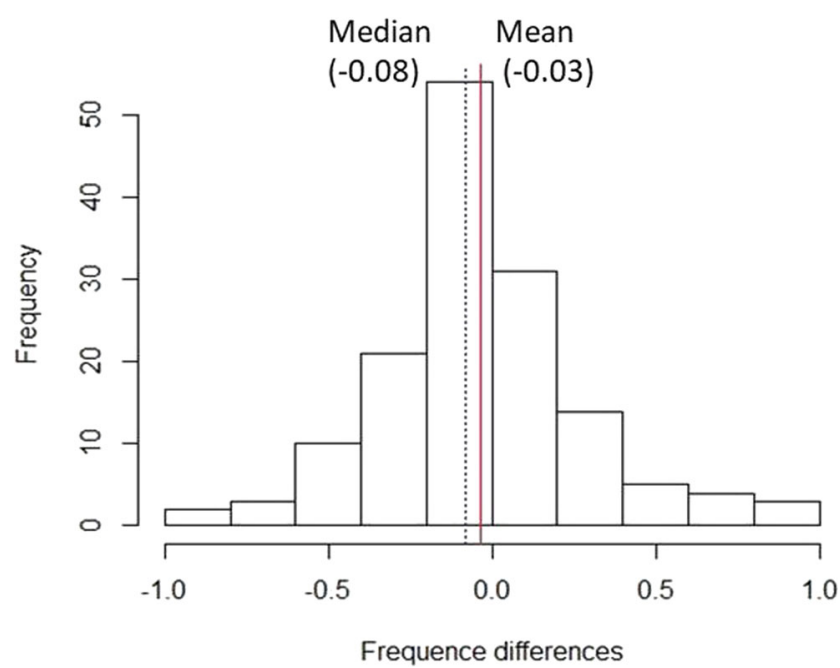

Fig. 8 Distribution across AFLP locus of the dominant phenotype (fragment presence) frequency differences between $J$. sabina and J. thurifera 
Fig. 9 Distribution of pollen grain sizes of the two hybrids (JTS14 and JTS19) and the parental species ( $J$. thurifera and $J$. sabina). The $\mathrm{x}$-axis represents the pollen grains diameters $(\mu \mathrm{m})$ and the $y$-axis represents the studied number of pollen grains

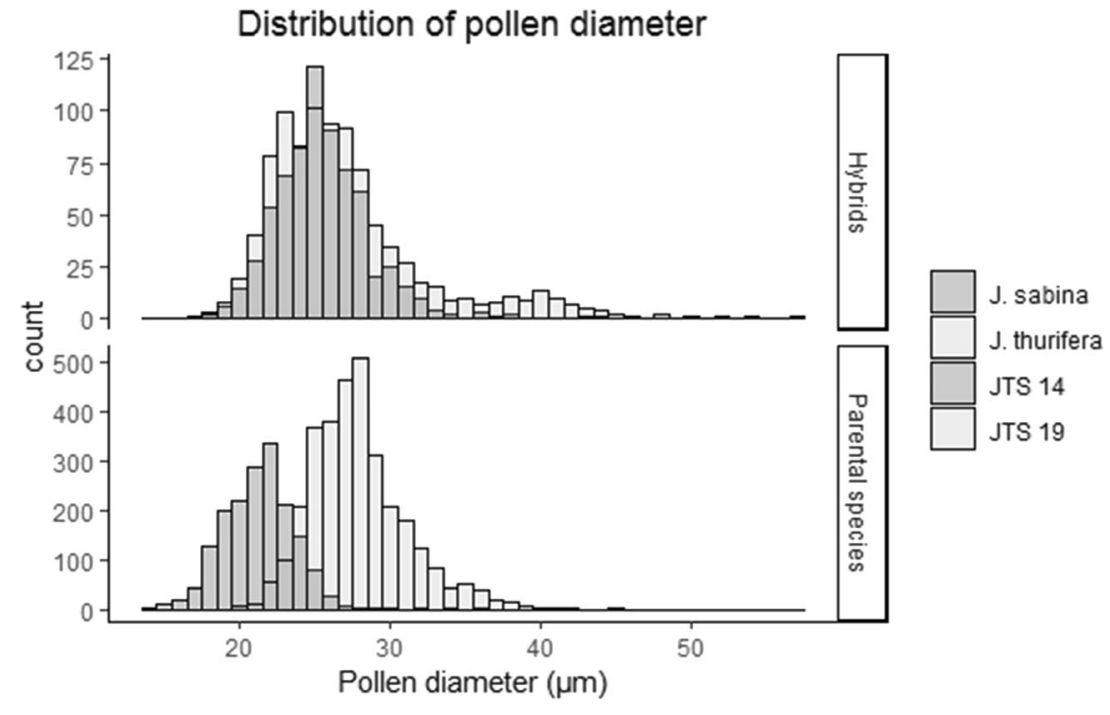

Table 7 Summary of pollen grains measurements of studied juniper trees from Saint Crépin. Max size and Min size correspond to the largest and smallest pollen grain sizes found in this study, respectively

\begin{tabular}{llllll}
\hline Species & Tree abbreviation & Total number of measured pollen grain & Mean pollen size $(\mu \mathrm{m})$ & Min size $(\mu \mathrm{m})$ & Max size $(\mu \mathrm{m})$ \\
\hline J. sabina & JS13, JS22, JS33 & 1712 & $21.3(\sigma=2.3)$ & 13.6 & 35.6 \\
J. thurifera & JT2, JT3, JT9 & 3171 & $27.8(\sigma=3.2)$ & 20 & 45.5 \\
J. sabina $\times$ J. thurifera & JTS14 & 686 & $25.4(\sigma=3.2)$ & 17 & 44 \\
$J$. sabina $\times$ J. thurifera & JTS19 & 928 & $27(\sigma=5.5)$ & 17.8 & 57 \\
\hline
\end{tabular}

\section{References}

Adams RP (2014) Junipers of the World: The genus Juniperus. Trafford Publishing, Bloomington

Adams RP (2019) Inheritance of chloroplasts and mitochondria in Conifers: a review of paternal, maternal, leakage and facultative inheritance. Phytologia 101:134-138

Adams RP, Farhat P, Shuka L, Siljak-Yakovlev S (2018) Discovery of Juniperus sabina var. balkanensis RP Adams and AN Tashev in Albania and relictual polymorphisms found in nrDNA. Phytologia. 100:187-194

Adams RP, Schwarzbach A, Tashev A (2016) Chloroplast capture by a new variety, Juniperus sabina var. balkanensis RP Adams and AN Tashev, from the Balkan peninsula: A putative stabilized relictual hybrid between $J$. sabina and ancestral J. thurifera. Phytologia 98: 100-111

Adams RP, Wingate D (2008) Hybridization between Juniperus bermudiana and J. virginiana in Bermuda. Phytologia 90: $123-213$

Adams RP, Anderson J, Rushforth K, Farhat P, Valentin N, SiljakYakovlev S (2019) The origin of Juniperus $x$ pfitzeriana, an allotetraploid hybrid of J. chinensis x J. sabina. Phytologia 111:164174

Adams RP, Schwarzbach AE (2006) A new variety of Juniperus sabina from Mongolia: J. sabina var. mongolensis. Phytologia 88:179-185

Ahuja MR (2005) Polyploidy in Gymnosperms: Revisited. Silvae Genet 54(2):59-69
Alexander MP (1969) Differential staining of aborted and nonaborted pollen. Stain Technol 44:117-122. https://doi.org/10.3109/ 10520296909063335

Aparicio JM, Uribe-Echebarría PM (2006) Juniperus $x$ palancianus, nuevo híbrido de la provincia de Castellón. Toll Negre 8:5-8

Aparicio JM, Uribe-Echebarría PM (2008) Juniperus x herragudensis, otro nuevo híbrido de la provincia de Castellón. Mainhardt 60:8385

Aparicio JM, Uribe-Echebarría PM (2009) Juniperus x cerropastorensis, nuevo híbrido entre Juniperus sabina L. Y Juniperus thurifera L. Toll Negre 11:6-13

Baack E, Melo MC, Rieseberg LH, Ortiz-Barrientos D (2015) The origins of reproductive isolation in plants. New Phytol 207:968-984

Bonin A, Bellemain E, Bronken Eidesen P, Pompanon F, Brochmann C, Taberlet P (2004) How to track and assess genotyping errors in population genetics studies. Mol Ecol 13:3261-3273

Bou Dagher-Kharrat M, Mariette S, Lefèvre F, Fady B, Grenier-de March G, Plomion C, Savouré A (2007) Geographical diversity and genetic relationships among Cedrus species estimated by AFLP. Tree Genet Genomes 3:275-285

Comai L (2005) The advantages and disadvantages of being polyploid. Nat Rev Genet 6:836-846

Coyne JA, Orr HA (2004) Speciation. Sinauer Associates Sunderland, Massachusetts

Díez-Garretas B, Asensi A (2014) The coastal plant communities of Juniperus macrocarpa in the Mediterranean region. Plant Biosyst 148:429-438. https://doi.org/10.1080/11263504.2013.778351 
Douaihy B, Sobierajska K, Jasińska AK, Boratyńska K, Ok T, Romo A, Machon N, Didukh Y, Bou Dagher-Kharrat M, Boratyński A (2012) Morphological versus molecular markers to describe variability in Juniperus excelsa subsp. excelsa (Cupressaceae). AoB Plants 2012

Doyle JJ, Doyle JL (1990) Isolation of plant DNA from fresh tissue. Focus 12:39-40

Evanno G, Regnaut S, Goudet J (2005) Detecting the number of clusters of individuals using the software structure: a simulation study. Mol Ecol 14:2611-2620. https://doi.org/10.1111/j.1365-294X.2005. 02553.x

Farhat P, Hidalgo O, Robert T, Siljak-Yakovlev S, Leitch IJ, Adams RP, Bou Dagher-Kharrat M (2019a) Polyploidy in the Conifer Genus Juniperus: an unexpectedly high rate. Front Plant Sci 10:676. https:// doi.org/10.3389/fpls.2019.00676

Farhat P, Siljak-Yakovlev S, Adams RP, Bou Dagher Kharrat M, Robert $\mathrm{T}$ (2019b) Genome size variation and polyploidy in the geographical range of Juniperus sabina L. (Cupressaceae). Bot Lett 166:134 143. https://doi.org/10.1080/23818107.2019.1613262

Farhat P, Takvorian N, Avramidou M, Garraud L, Adams RP, SiljakYakovlev S, Bou Dagher Kharrat M, Robert T (2020) Data from: first evidence for allotriploid hybrids between Juniperus thurifera and $J$. sabina in a sympatric area in the French Alps. Dryad [Dataset]. https://doi.org/10.5061/dryad.h44j0zpgk

Farjon A (2005) A monograph of Cupressaceae and Sciadopitys. Royal Botanic Gardens, Kew, Kew

Garraud L, Abdulhak S (2014) Approche syntaxonomique et écologique des formations à Genévrier thurifère (Juniperus thurifera L.) dans les Alpes françaises. Ecol Mediterr 40:61-74

Giles N (1941) Spontaneous chromosome aberrations in triploid Tradescantia hybrids. Genetics 26:632-649

Hall MT, Mukherjee A, Crowley WR (1973) Chromosome counts in cultivated junipers. J Arnold Arboretum 54:369-376

Hipkins VD, Krutovskii KV, Strauss S (1994) Organelle genomes in conifers: structure, evolution, and diversity. For Genet 1:179-189

Husband BC, Sabara HA (2004) Reproductive isolation between autotetraploids and their diploid progenitors in fireweed, Chamerion angustifolium (Onagraceae). New Phytol 161:703-713

Husband BC, Baldwin SJ, Suda J (2013) The incidence of polyploidy in natural plant populations: major patterns and evolutionary processes. In: Greilhuber J, Dolezel J, Wendel JF (eds) Plant genome diversity volume 2: physical structure, behaviour and evolution of plant genomes. Springer, Vienna, pp 255-276

Jakobsson M, Rosenberg NA (2007) CLUMPP: a cluster matching and permutation program for dealing with label switching and multimodality in analysis of population structure. Bioinformatics 23:1801-1806. https://doi.org/10.1093/bioinformatics/ btm233\%JBioinformatics

Karlsdóttir L, Hallsdóttir M, Thórsson AT, Anamthawat-Jónsson K (2008) Characteristics of pollen from natural triploid Betula hybrids. Grana 47:52-59

Katsiotis A, Forsberg R (1995) Pollen grain size in four ploidy levels of genus Avena. Euphytica 83:103-108

Kerbs B, Ressler J, Kelly JK, Mort ME, Santos-Guerra A, Gibson MJ, Caujapé-Castells J, Crawford DJ, Hiscock SJ (2017) The potential role of hybridization in diversification and speciation in an insular plant lineage: insights from synthetic interspecific hybrids. AoB Plants 9:plx043

Kukowski KR, Schwinning S, Schwartz BF (2013) Hydraulic responses to extreme drought conditions in three co-dominant tree species in shallow soil over bedrock. Oecologia 171:819-830

Lebreton P, Garraud L, Genis J-M (2013) Contribution à la connaissance écologique du Genévrier thurifère, comparé aux autres espèces du genre Juniperus dans le sud-est de la France continentale. Ecol Mediterr 39:55-59

Mallet J (2007) Hybrid speciation. Nature 446:279-283
Mao K, Hao G, Liu J, Adams R, Milne R (2010) Diversification and biogeography of Juniperus (Cupressaceae): variable diversification rates and multiple intercontinental dispersals. New Phytol 188(1): 254-272

Marques I, Loureiro J, Draper D, Castro M, Castro S (2017) How much do we know about the frequency of hybridisation and polyploidy in the Mediterranean region? Plant Biol 20:21-37

Mathaux C, Mandin J-P, Oberlin C, Edouard J-L, Gauquelin T, Guibal F (2016) Ancient juniper trees growing on cliffs: toward a long Mediterranean tree-ring chronology. Dendrochronologia 37:79-88

Neale DB, Sederoff R (1989) Paternal inheritance of chloroplast DNA and maternal inheritance of mitochondrial DNA in loblolly pine. Theor Appl Genet 77:212-216

Neale DB, Wheeler NC (2019) The conifers: genomes, variation and evolution. Springer Nature Cham, Switzerland

Noble DL (1990) Juniperus scopulorum Sarg. Rocky Mountain Juniper Silvics N Am 1:116-126

Otto SP, Whitton J (2000) Polyploid incidence and evolution. Annu Rev Genet 34:401-437

Perez-Latorre A, Cabezudo B (2009) Gimnospermas. in Blanca G. et al. eds. Flora Vascular De Andalucía Oriental. Volumen 1. Sevilla, España: Consejería de Medio Ambiente, Junta de Andalucía, 77-88.

Pichot C, El Maâtaoui M (2000) Unreduced diploid nuclei in Cupressus dupreziana A. Camus pollen. Theor Appl Genet 101:574-579

Pinna MS, Cañadas EM, Fenu G, Bacchetta G (2015) The European Juniperus habitat in the Sardinian coastal dunes: implication for conservation. Estuar Coast Shelf Sci 164:214-220. https://doi.org/ 10.1016/j.ecss.2015.07.032

Ramsey J, Schemske DW (1998) Pathways, mechanisms, and rates of polyploid formation in flowering plants. Annu Rev Ecol Evol Syst 29:467-501

Rawat YS, Everson CS (2012) Ecological status and uses of juniper species in the cold desert environment of the Lahaul valley, Northwestern Himalaya, India. J Mt Sci 9:676-686

Romo A, Hidalgo O, Boratyński A, Sobierajska K, Jasińska AK, Vallès J, Garnatje T (2013) Genome size and ploidy levels in highly fragmented habitats: the case of western Mediterranean Juniperus (Cupressaceae) with special emphasis on J. thurifera L. Tree Genet Genomes 9:587-599. https://doi.org/10.1007/s11295-012-0581-9

Sakaguchi S, Tsumura Y, Crisp MD, Bowman DMJS, Isagi Y (2014) Genetic evidence for paternal inheritance of the chloroplast in four Australian Callitris species (Cupressaceae). J For Res 19:244-248. https://doi.org/10.1007/s10310-012-0384-8

Soltis PS, Soltis DE (2009) The role of hybridization in plant speciation. Annu Rev Plant Biol 60:561-588

Srisuwan S, Sihachakr D, Martín J, Vallès J, Ressayre A, Brown SC, Siljak-Yakovlev S (2019) Change in nuclear DNA content and pollen size with polyploidisation in the sweet potato (Ipomoea batatas, Convolvulaceae) complex. Plant Biol 21:237-247. https://doi.org/ 10.1111/plb.12945

Terry RG, Nowak RS, Tausch RJ (2000) Genetic variation in chloroplast and nuclear ribosomal DNA in Utah juniper (Juniperus osteosperma, Cupressaceae): evidence for interspecific gene flow. Am J Bot 87:250-258

Vallès J, Garnatje T, Robin O, Siljak-Yakovlev S (2015) Molecular cytogenetic studies in western Mediterranean Juniperus (Cupressaceae): a constant model of GC-rich chromosomal regions and rDNA loci with evidences for paleopolyploidy. Tree Genet Genomes 11:1-8

Vekemans X (2002) AFLP-SURV 1.0: A program for genetic diversity analysis with AFLP (and RAPD) population data. http://www.ulb. ac.be/sciences/lagev/aflp-surv.html: Distributed by author. 
Laboratoire de Génétique et Ecologie Végétale, Universite' Libre de Bruxelles, Belgium

Van de Peer Y, Mizrachi E, Marchal K (2017) The evolutionary significance of polyploidy. Nat Rev Genet 18(7):1-14

Vos P, Hogers R, Bleeker M, Reijans M, van de Lee T, Hornes M, Frijters A, Pot J, Peleman J, Kuiper M (1995) AFLP: a new technique for DNA fingerprinting. Nucleic Acids Res 23:4407-4414
Whitney DK, Ahern RJ, Campbell GL, Albert PL, King SM (2010) Patterns of hybridization in plants. Perspect Plant Ecolo Evol Syst $12: 175-182$

Publisher's note Springer Nature remains neutral with regard to jurisdictional claims in published maps and institutional affiliations. 